\title{
ERRATUM
}

\section{Erratum to: Formation of Low-Friction Particle/Polymer Composite Tribofilms by Tribopolymerization}

\author{
Fredrik Svahn $\cdot$ Stefan Csillag
}

Published online: 9 February 2011

(C) Springer Science+Business Media, LLC 2011

\section{Erratum to: Tribol Lett}

DOI 10.1007/s11249-010-9721-2

The original version of this article unfortunately contained a mistake. The values of the wear rates given Table 2 and
Figure 2 have been corrected because of a systematic calculation error giving wrong values by a factor of 16 .

Table 2 Summary of friction coefficients $(\mu)$ and wear rates from reciprocal sliding tests of different additives in PAO

\begin{tabular}{llllc}
\hline & $\mu(3 \mathrm{~Hz})$ & $\begin{array}{l}\text { Wear rate }(3 \mathrm{~Hz}) \\
\left(\mu \mathrm{m}^{3} / \mathrm{Nm}\right)\end{array}$ & $\mu(10 \mathrm{~Hz})$ & $\begin{array}{l}\text { Wear rate }(10 \mathrm{~Hz}) \\
\left(\mu \mathrm{m}^{3} / \mathrm{Nm}\right)\end{array}$ \\
\hline No additives & 0.12 & 40 & 0.11 & 25 \\
Monomer & 0.077 & 13 & 0.069 & 3.4 \\
IF (1\%) & 0.092 & 45 & 0.071 & 5.6 \\
IF (5\%) & 0.083 & 27 & 0.071 & 9.8 \\
Monomer + IF & 0.065 & 7.2 & 0.054 & 1.4 \\
2H (1\%) & 0.13 & 101 & 0.066 & 4.1 \\
2H (5\%) & 0.14 & 106 & 0.073 & 8.5 \\
Monomer + 2H & 0.065 & 8.7 & 0.057 & 2.5 \\
Zn-DTP & 0.09 & 11 & 0.073 & 3.7 \\
Zn-DTP + IF & 0.097 & 7.8 & 0.079 & 4.0
\end{tabular}

Friction coefficients are mean values from $2-5$ recordings, where each value is a mean for the last $50 \%$ of the recording. Wear rates are a mean from 2-3 tests. Scatterings are illustrated in Fig. 3. Load $10 \mathrm{~N}$ (1 GPa)

The online version of the original article can be found under doi: 10.1007/s11249-010-9721-2.

F. Svahn $(\varangle) \cdot$ S. Csillag

Department of Physics, Stockholm University, SE 10691

Stockholm, Sweden

e-mail: fredrik.svahn@angstrom.uu.se 
Fig. 2 Schematic presentation of the results from reciprocal sliding tests in PAO, given in Table 2, also showing the different spreads in the results; the highest and lowest observed friction coefficient and wear rate for each additive combination. Sliding speed of (a) $3 \mathrm{~Hz}$ and (b) $10 \mathrm{~Hz}$. Load $10 \mathrm{~N}(1 \mathrm{GPa})$

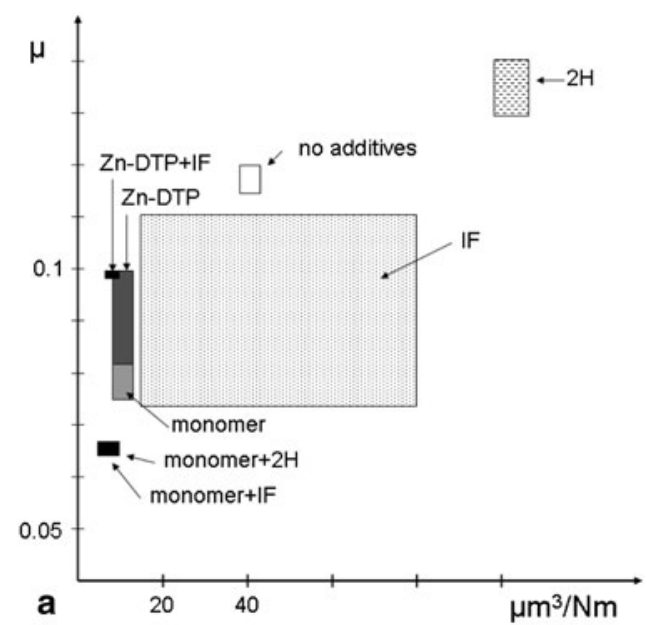

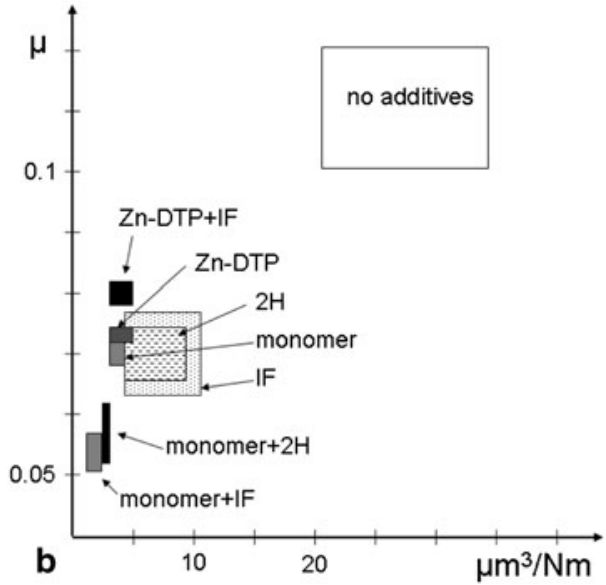

